
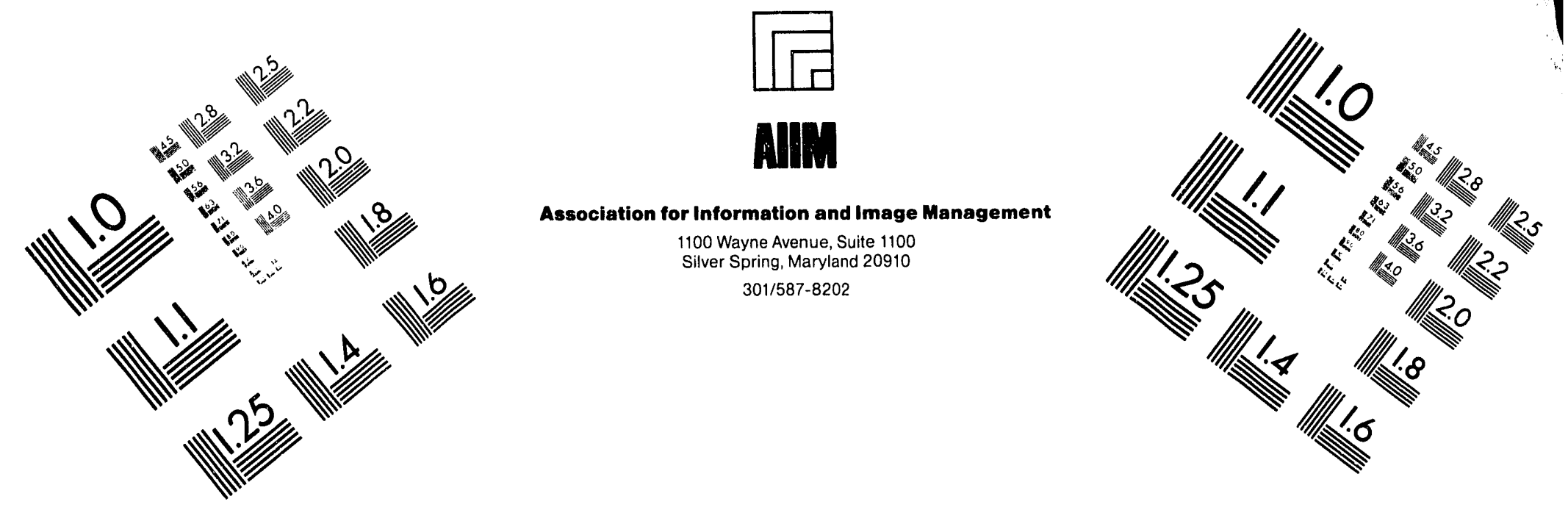

Centimeter

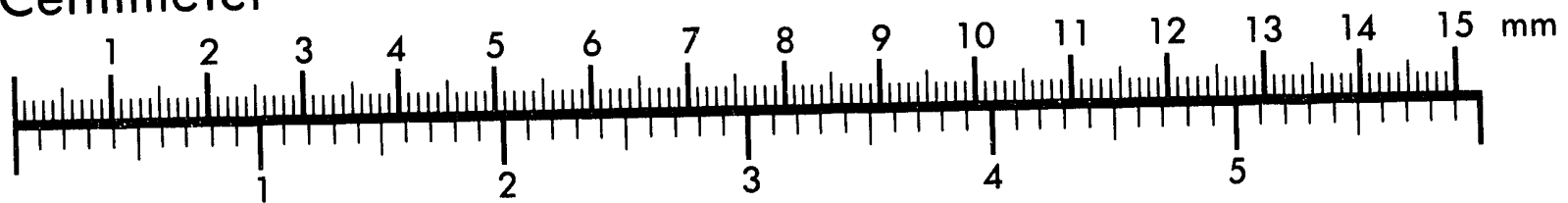
Inches
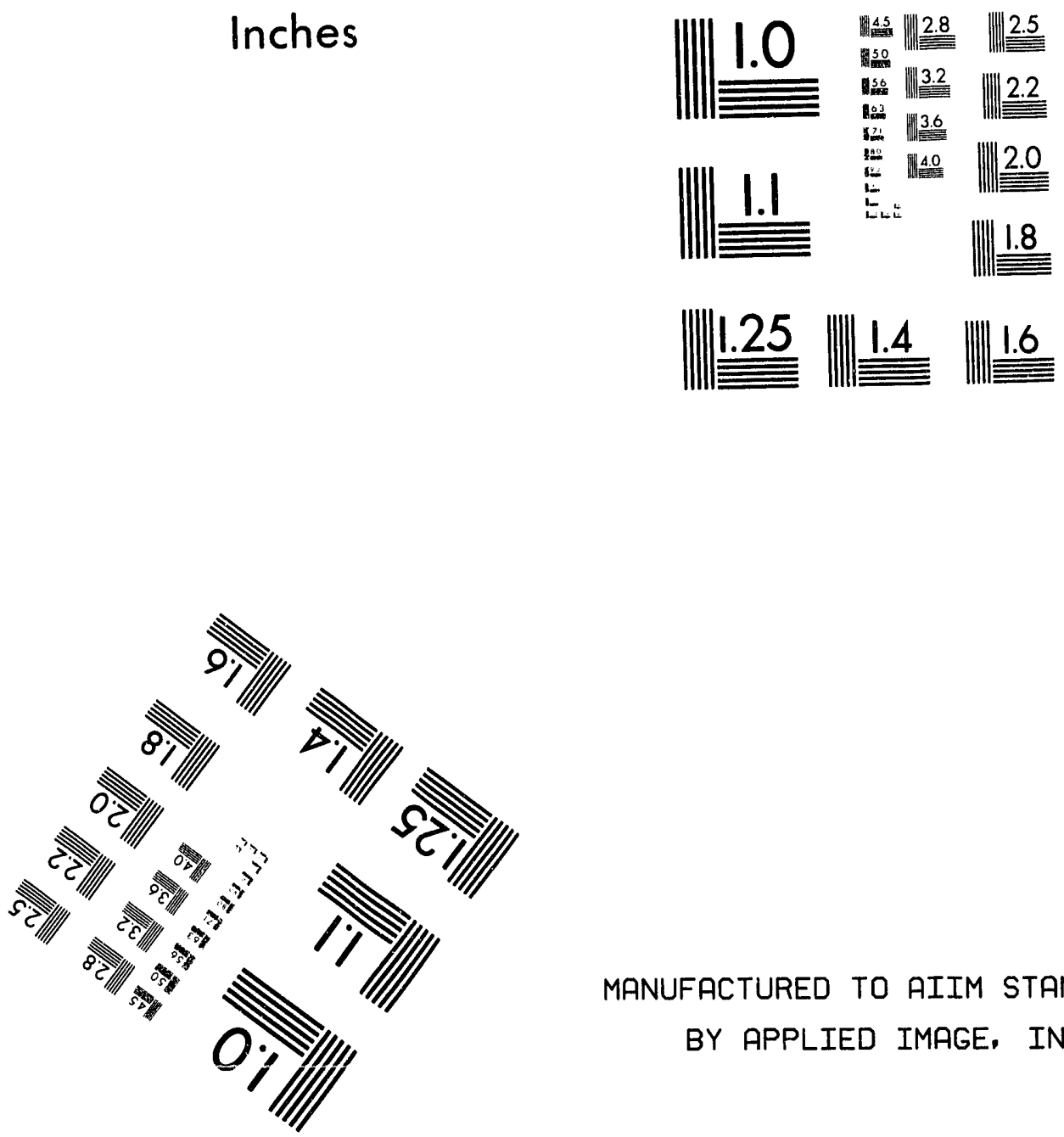

MANUFACTURED TO AIIM STANDARDS

BY APPLIED IMAGE, INC.

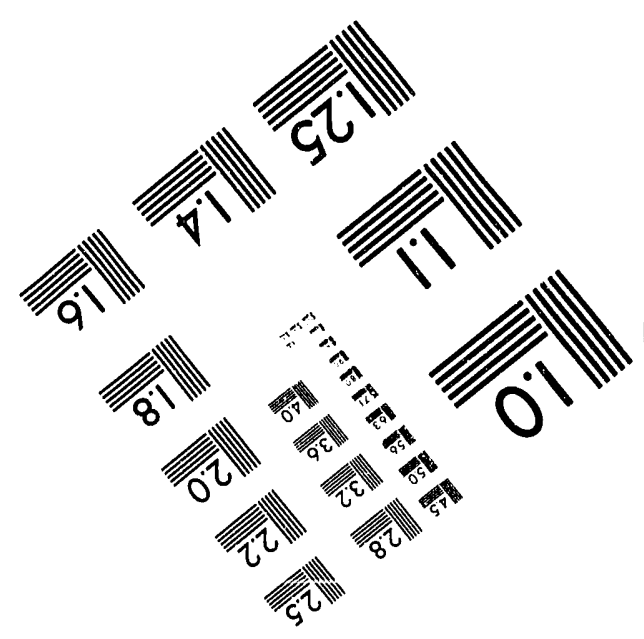



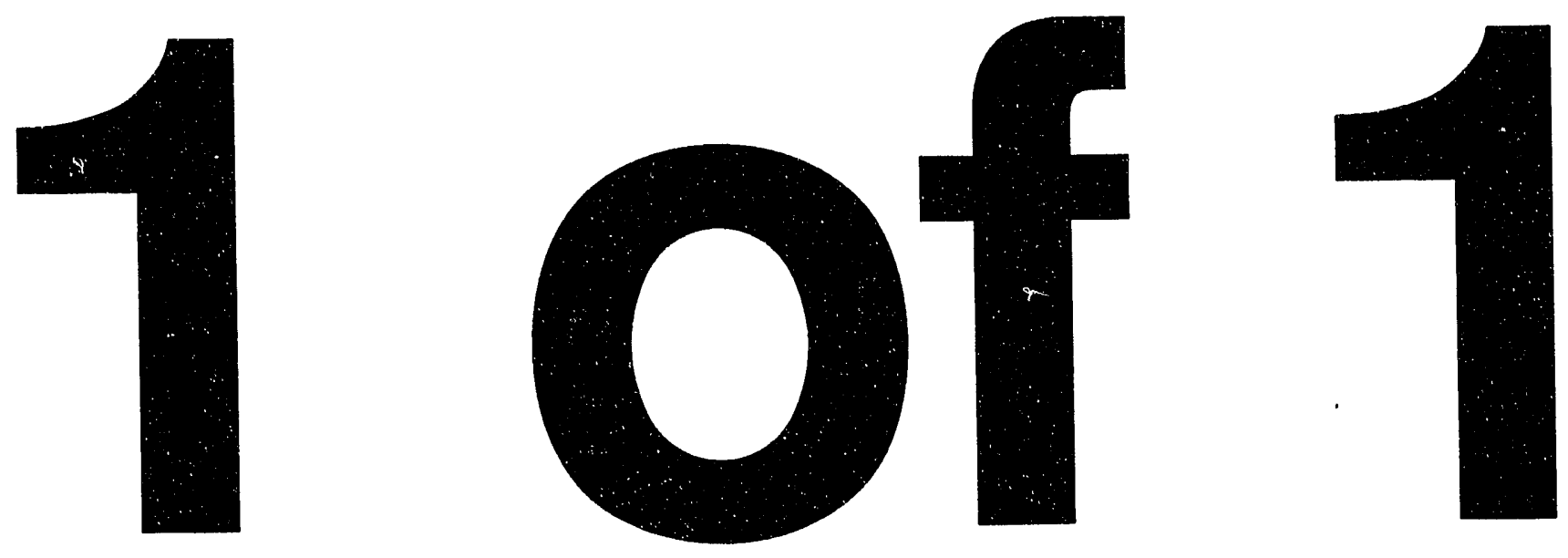


\section{THIN Ni SILICIDE FORMATION BY LOW TEMPERATURE-INDUCED METAL ATOM REACTION WITH ION IMPLANTED AMORPHOUS SILICON}

YU.N. EROKHIN ${ }^{*}$, B.K. PATNAIK ${ }^{2}$, S. PRAMANICK ${ }^{1}$, F. HONG ${ }^{1}$, C.W. WHITE ${ }^{3}$, and G.A. ROZGONYI ${ }^{1}$

1Department of Materials Science \& Engineering, North Carolina State University, Raleigh, NC

27695-7916 3255

30ak Ridge National Laboratory, Oak Ridge, TN 37831-6057

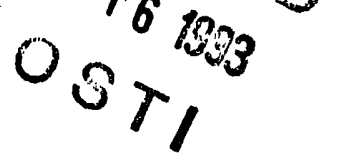

\section{ABSTRACT}

We have extended our recent work [1,2] on buried silicide formation by Ni diffusion into a buried amorphous silicon layer to the case where silicide formation is at lower temperatures on silicon substrates which have been preamorphized. The reaction of metal atoms from a $12 \mathrm{~nm} \mathrm{Ni}$ film evaporated on top of a $65 \mathrm{~nm}$ thick surface amorphous layer formed by $35 \mathrm{keV} \mathrm{Si}{ }^{+}$ion implantation has been investigated at temperature $\leq 400{ }^{\circ} \mathrm{C}$. Rutherford Backscattering Spectrometry (RBS) with channeling, cross-sectional trarismission electron microscopy (XTEM), $X$-ray diffraction and four-point-probe measurements were used to determine the structure, interfacial morphology, composition and resistivity of the silicide films. It has been found that an increased rate of silicidation occurs for amorphous silicon with respect to crystalline areas permitting a selective control of the silicon area to be contacted during silicide growth. Vacuum furnace annealing at $360^{\circ} \mathrm{C}$ for 8 hours followed by an additional step at $400^{\circ} \mathrm{C}$ fur one hour produces a continuos $\mathrm{NiSi}_{2}$ layer with a resistivity $44 \mu \Omega \mathrm{cm}$.

\section{INTRODUCTION}

The scaling to submicron CMOS and BiCMOS devices has created a stringent requirement for formation of silicided ultrashallow $\mathrm{p}^{+} / \mathrm{n}$ and $\mathrm{n}^{+} / \mathrm{p}$ junctions. A current problem is the growth of thin, uniform contact silicide layers with smooth silicide-to-silicon interfaces, while a strict control over the silicon consumption must be maintained in order to avoid degradation of junction characteristics. The thermal stability of nanoscale silicide films is also of great importance for microelectronics technology. It is known that the rate of silicidation is higher in the case where metal atoms react with amorphous rather than crystalline silicon. This is attributed to the excess free energy of the amorphous silicon $[3,4]$. Thus, for silicide growth at temperatures, which are below the temperature of a-Si SPE, the silicide will essentially be confined within the original amorphous layer. The sharpness of the silicide interface will be influenced in this case by the sharpness of the original a-Si to c-Si interface.

$\mathrm{Ni}$ was selected as the metal in this work since it is known to form a silicide at a lower temperature when reacted with a-Si with respect to c-Si [5]. Specifically, the $\mathrm{NiSi}_{2}$ phase formed on a-Si after thermal annealing at temperatures from $350-500{ }^{\circ} \mathrm{C}$, while $600{ }^{\circ} \mathrm{C}$ is typically required on crystalline silicon for the silicon rich $\mathrm{NiSi}_{2}$ phase to dominate. Additionally, confinement of the $\mathrm{Ni}$ silicide within a preamorphized layer is likely to provide improved performance for silicided shallow $\mathrm{p}$ - $\mathrm{n}$ junctions where nickel disilicide interface roughness is known to cause leaky junctions, e.g., in Ref. [6] the silicide roughness was one third of the total silicide thickness.

* permanent address: Institute of Microelectronics Technology, 142432, Chernogolovka, Moscow rgn., Russia

\section{MASTR}

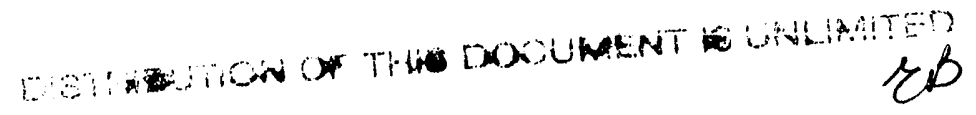




\section{EXPERIMENTAL}

$\mathrm{N}$-type (100) Si substrates with a resistivity $4 \Omega \mathrm{cm}$ were implanted with $35 \mathrm{keV} \mathrm{Si}^{+}$ions to a dose of $1.5^{*} 10^{15} \mathrm{~cm}^{-2}$ in order to form a continuous $65 \mathrm{~nm}$ thick amorphous surface layer as confirmed by RBS channeling measurements. Prior to metal evaporation, samples were chemically cleaned in $4 \% \mathrm{HF}$ acid for $5 \mathrm{~min}$ and rinsed by deionized water. Nickel films were deposited using a thermal evaporation system. Film thickness during evaporation was controlled by a Kurt J. Lesker model QXM-500 thickness monitor. The pressure during evaporation was $2 * 10^{-6}$ Torr. Heat treatments were carried out in the temperature range from 360 to $400{ }^{\circ} \mathrm{C}$ in a vacuum furnace with a residual pressure in the $10^{-6}$ Torr range. RBS channeling with $2.0 \mathrm{MeV}$ ${ }^{4} \mathrm{He}^{+}$probe ions, X-ray diffraction and XTEM techniques were used to analyze structures and compositions. The sheet resistance of the film was measured by a four-point-probe technique.

\section{RESULTS AND DISCUSSION}

Figure 1 shows RBS aligned and random spectra of a sample which had an initial $12 \mathrm{~nm} \mathrm{Ni}$ film deposited on top of a $65 \mathrm{~nm}$ amorphous Si layer, following thermal annealing at $360^{\circ} \mathrm{C}$ for 8 hours. From this spectra it is seen that all $\mathrm{Ni}$ atoms from the deposited film have reacted with the amorphous silicon. The estimated depth of the silicide layer was about $50 \mathrm{~nm}$. Comparing the height of the $\mathrm{Ni}$ and Si peaks, it can be concluded that the dominant phase in the silicide layer is $\mathrm{NiSi}_{2}$. This is also confirmed by the of X-ray diffraction measurements presented in Fig. 2, where diffraction peaks corresponding to the Ni disilicide phase, the Si substrate, and a peak attributed to the sample holder are present in the spectrum. This is in contrast with the results of Mohadjeri et al. [7.8] who observed only the monosilicide phase after $350^{\circ} \mathrm{C}$ for 1 hour annealing of structures with 46 to $60 \mathrm{~nm}$ thick Ni films deposited on amorphous silicon either evaporated on a (111) Si substrate, or formed by $\mathrm{As}^{+}$ion implantation. In those experiments annealing at $425^{\circ} \mathrm{C}$ for deposited a-Si, and at $700^{\circ} \mathrm{C}$ for implantation amorphized silicon was necessary to form a homogeneous $\mathrm{NiSi}_{2}$ layer. We attribute the difference between these results and ours to the considerably longer annealing times ( $8 \mathrm{hrs}$ vs $1 \mathrm{hr}$ ), the smaller thickness of the metal film (12 vs $>45 \mathrm{~nm}$ ), effects of impurities in their amorphous layers, and and the different reaction barriers presented by (111) Si substrates. From RBS measurements we determined that the thickness of the as-deposited $\mathrm{Ni}$ film, $12 \mathrm{~nm}$, is slightly lower than would be necessary to form the $\mathrm{NiSi}_{2}$ phase through the whole amorphous layer. Thus, some residual amorphous silicon was left in the vicinity of the original amorphous to crystalline interface. This conclusion is based on the shape of the RBS channeling spectrum in Fig.1 and the XTEM micrograph presented in Fig.3. Figure 4

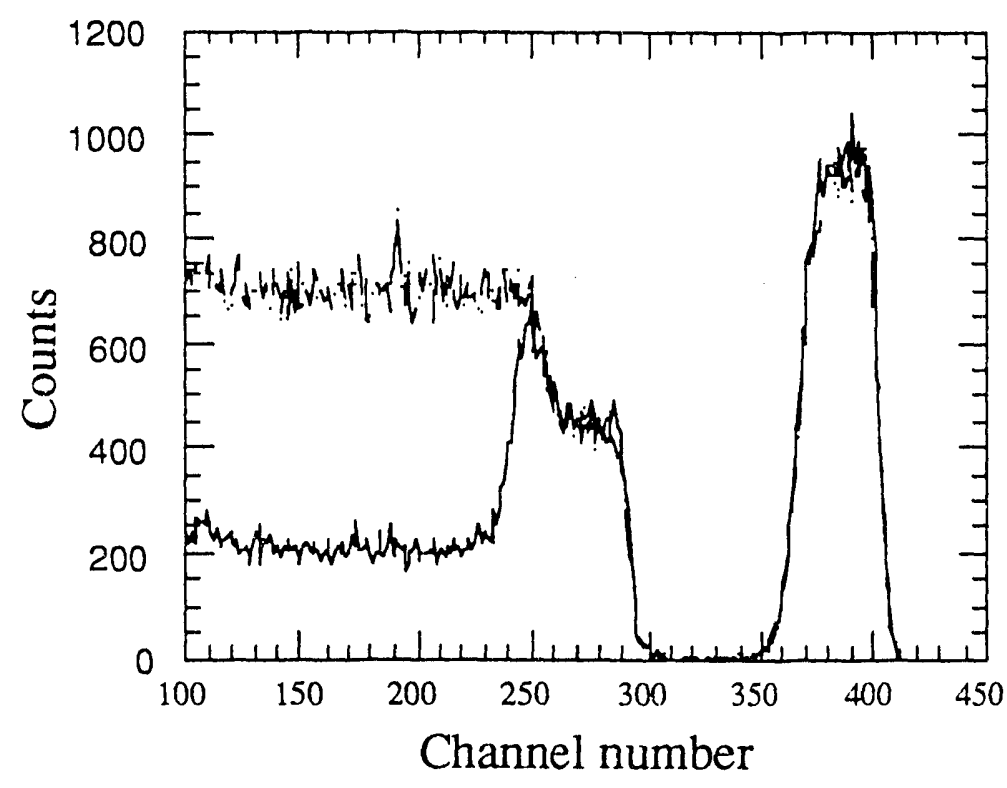

Fig.1. $2.0 \mathrm{MeV}{ }^{4} \mathrm{He}^{+}$RBS random and channeling spectra of $\mathrm{Ni}(12 \mathrm{~nm}) / \mathrm{a}-\mathrm{Si} / \mathrm{c}-\mathrm{Si}$ (substrate) structure after thermal annealing at $360^{\circ} \mathrm{C}$ for 8 hours, scattering angle $145^{\circ}$. 


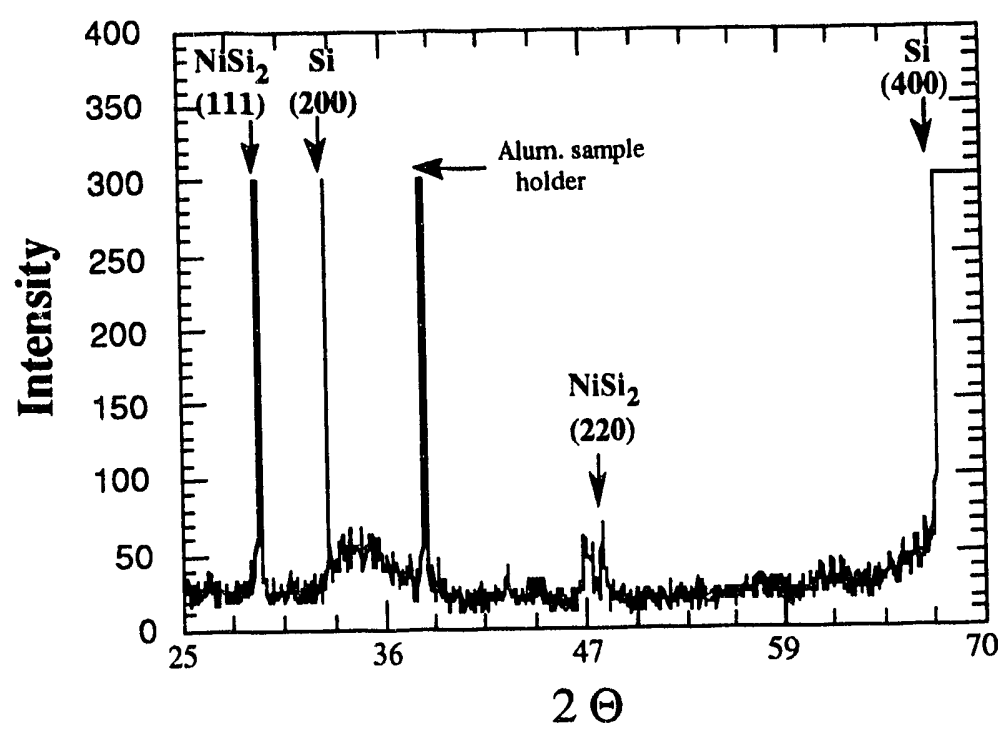

Fig.2. XRD spectra of Ni silicide formed after thermal annealing at $360^{\circ} \mathrm{C}$ for 8 hours.

is a XTEM micrograph of an area where the nickel disilicide phase formed completely through the amorphous silicon and reached the crystalline substrate. An important feature is that upon reaching the c-Si substrate the $\mathrm{NiSi}_{2}$ layer did not penetrate further. This is due to the absence of a driving force, which, in the case of reaction with amorphous silicon, is provided by an excess free energy ranging from 11 to $20 \mathrm{~kJ} / \mathrm{mol}[3,4]$. For this reason, once the $\mathrm{NiSi}_{2}$ phase reached the crystalline interface it proceeds to grow laterally, thereby consuming the adjacent amorphous silicon. This phenomenon may be effectively used to control the thickness of silicon consumed during the silicidation reaction and avoiding silicide-to-silicon interface roughening, which is known to be particularly severe on (100) silicon [6].

After consuming all the deposited metal film, additional $\mathrm{Ni}$ atoms required to continue a reaction with amorphous silicon are provided through decomposition of previously formed $\mathrm{NiSi}_{2}$. This causes the formation of local areas of silicon which are epitaxially recrystallized with respect to the substrate. These areas are located within the former amorphous region, see the arrow $\mathrm{R}-\mathrm{Si}$ in Fig. 4. This result is in accordance with previously observed [8,9] silicidation enhanced recrystallization of amorphous silicon at temperatures considerably lower than those of silicon

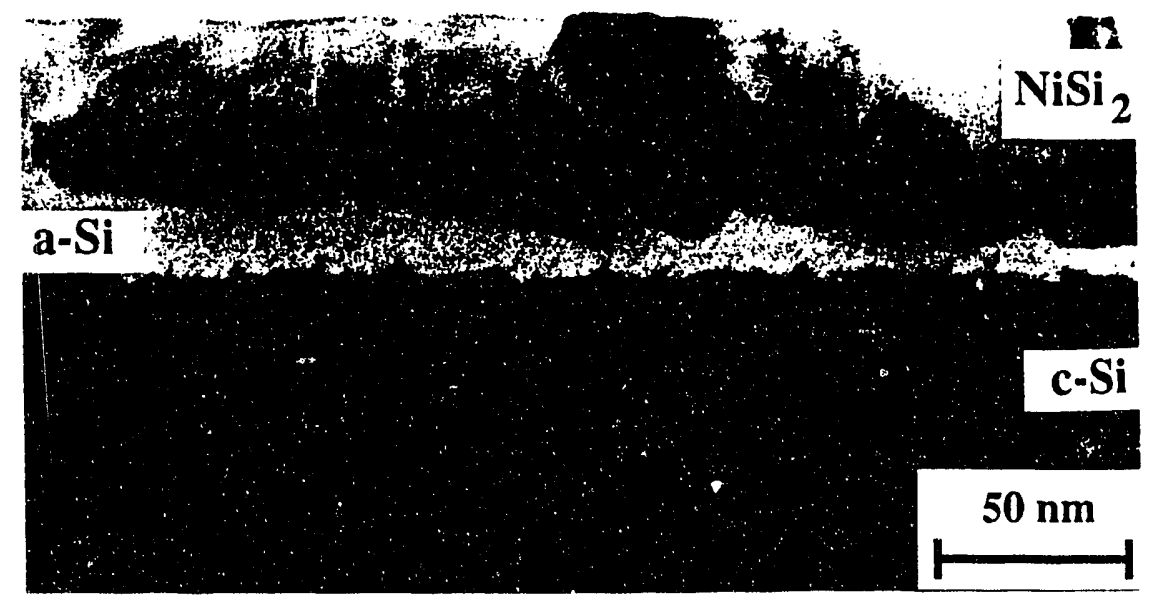

Fig.3. XTEM bright field micrograph of $\mathrm{Ni}(12 \mathrm{~nm}) / \mathrm{a}-\mathrm{Si} / \mathrm{c}-\mathrm{Si}$ (substrate) structure after thermal annealing at $360^{\circ} \mathrm{C}$ for 8 hours. 


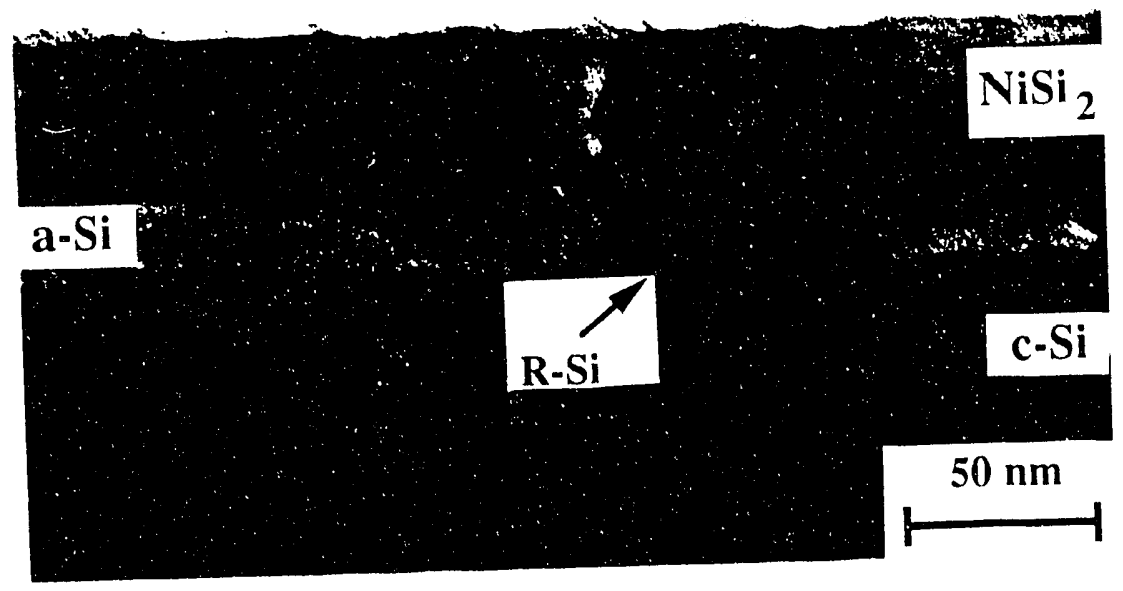

Fig.4. XTEM bright field micrograph of $\mathrm{Ni}(12 \mathrm{~nm}) / \mathrm{a}-\mathrm{Si} / \mathrm{c}-\mathrm{Si}$ (substrate) structure after thermal annealing at $360^{\circ} \mathrm{C}$ for 8 hours. $\mathrm{R}-\mathrm{Si}$ indicates silicon recrystallized by silicidation reaction.

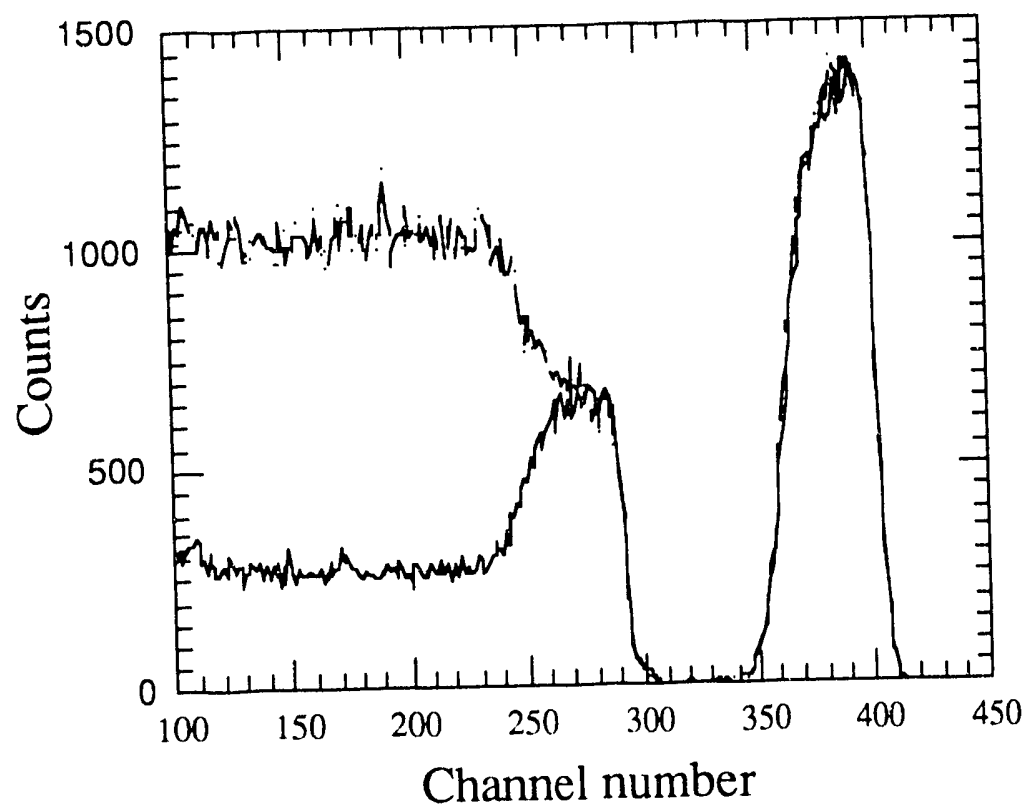

Fig.5. $2.0 \mathrm{MeV}{ }^{4} \mathrm{He}^{+} \mathrm{RBS}$ random and channeling spectra of $\mathrm{Ni}(12 \mathrm{~nm}) / \mathrm{a}-\mathrm{Si} / \mathrm{c}-\mathrm{Si}$ (substrate) structure after additional thermal annealing at $360^{\circ} \mathrm{C}$ for 8 hours, scattering angle $145^{\circ}$.

silicon SPE. In our experiments the thickness of Ni film deposited on top of a a-Si was smaller than it would be necessary to grow $\mathrm{NiSi}_{2}$ completely through the original a-Si layer. For this reason $\mathrm{NiSi}_{2}-\mathrm{c}-\mathrm{Si}$ interface sharpness was not determined by the sharpness of original interface between amorphous and crystalline layers, but by the process of silicidation-induced recrystallization of a-Si, involving decomposition of previously formed nickel disilicide. This prevented us from achieving in the present experiment a major improvement of silicide-to-silicon interface homogeneity with respect to Ni reaction with a crystalline (100) Si substrate. Since no $\mathrm{NiSi}_{2}$ is observed beyond the original a-Si layer in our structures, we believe a more exact matching of the deposited $\mathrm{Ni}$ thickness with a-Si thickness would lead to a smoth interface. An 
additional annealing step at $400^{\circ} \mathrm{C}$ for 1 hour leads to completion of the epitaxial recrystallization of the residual amorphous layer left after the first anneal. This conclusion is based on comparison of RBS spectra presented in Fig.5 and Fig.1. The resistivity of the $\mathrm{NiSi}_{2}$ film was $44 \mu \Omega \mathrm{cm}$, as determined by a four-point-probe technique.

\section{CONCLUSIONS}

We have observed formation of continuous $50 \mathrm{~nm}$ thick polycrystalline silicide layers by thermally induced reaction of deposited $\mathrm{Ni}$ film with preamorphized Si substrate at a temperature as low as $360^{\circ} \mathrm{C}$. The silicide layer was completely confined within the $65 \mathrm{~nm}$ thick amorphous layer formed by $\mathrm{Si}^{+}$ion implantation. After first annealing at $360^{\circ} \mathrm{C}$ for 8 hours, all the $\mathrm{Ni}$ atoms reacted with amorphous silicon, forming mostly $\mathrm{NiSi}_{2}$ phase, where resistivity was found to be $44 \mu \Omega \mathrm{cm}$. Some non-reacted amorphous silicon was left within the original amorphous to crystalline interface due to lack of $\mathrm{Ni}$ to consume all the amorphous silicon. An additional annealing step at $400^{\circ} \mathrm{C}$ for 1 hour leads to complete epitaxial recrystallization of the residual amorphous regions due to lateral $\mathrm{Ni}$ disilicide growth. $\mathrm{Ni}$ atoms necessary to complete the reaction are provided due to partial decomposition of the already formed $\mathrm{NiSi}_{2}$ layer. But even in this case, no silicide was found beyond the original a-Si layer.

\section{REFERENCES}

[1]. Yu. N. Erokhin, R. Grotzschel, S.R. Oktyabrsky, S. Roorda, W.C. Sinke in Phase Formation and Modification by Beam-Solid Interactions, edited by G.S. Was, L.E. Rehn, and D.M. Follstaedt. (Mat. Res. Soc. Symp. Proc. 235, Pittsburg, PA 1991), p.313.

[2]. Yu. N. Erokhin, R. Grotzschel, S.R. Oktyabrsly, S. Roorda, W.C. Sinke. Materials Science and Engineering B12, 103 (1992).

[3]. J.C.C. Fan and H.Anderson, J.Appl.Phys., 52, 4003 (1981).

[4]. W.C. Sinke, S. Roorda and F. Saris, J. Mater. Res., 3, 1203 (1988).

[5]. L.A. Clevenger, C.V. Thompson, K.N. Tu, J. Appl. Phys., 67, 2894.

[6]. C.M. Osburn, Journal of Electronic Materials, 19, 67 (1990).

[7]. B. Mohadjeri, J. Linnors, B.S. Svensson, M. Ostling, S. Johansson, F.M. d'Heurle in Advanced Metallization and Processing for Semiconductor Devices and Circuits - II, edited by A. Katz, Sh.P. Murarka, Yv.I. Nissim and J.M.E. Harper. (Mat. Res. Soc. Symp. Proc. 260, Pittsburg, PA 1991), p.405.

[8]. B. Mohadjeri, J. Linnros, B.S. Svensson, M. Ostling, Phys. Rev. Lett., 68, 1872 (1992).

[9]. C. Hayzelden, J.L. Batstone, R.C. Cammarata, Appl. Phys. Lett. 60, 225 (1992).

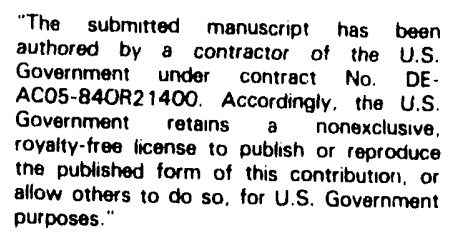



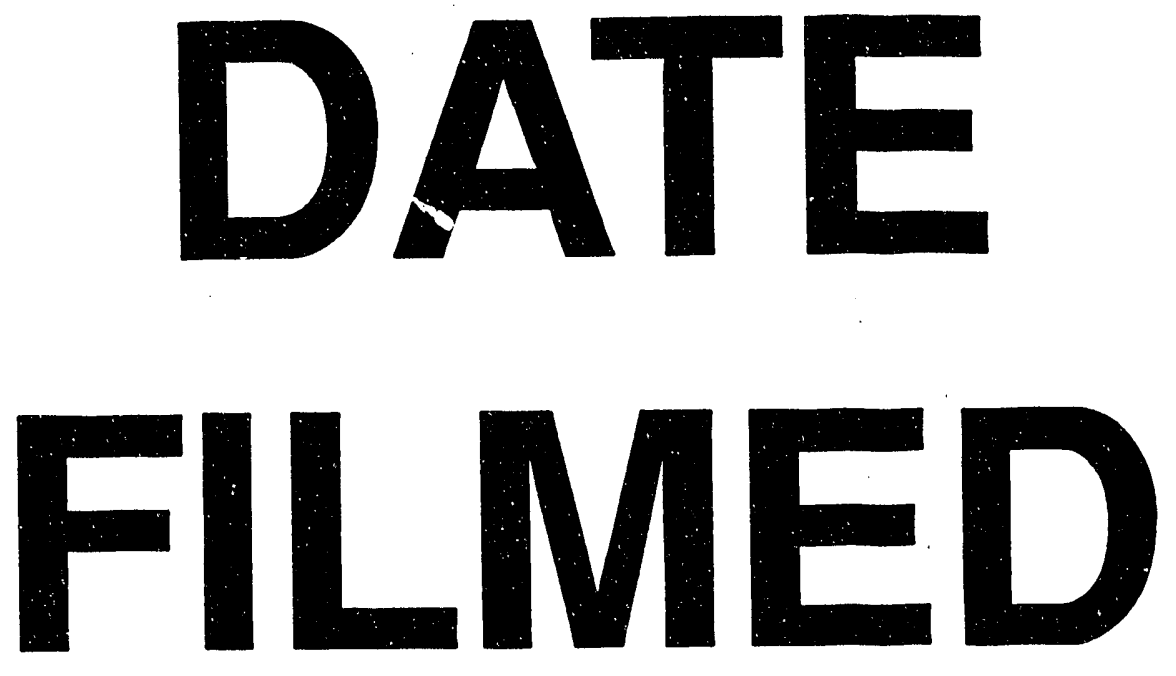

$8 / 17 / 93$
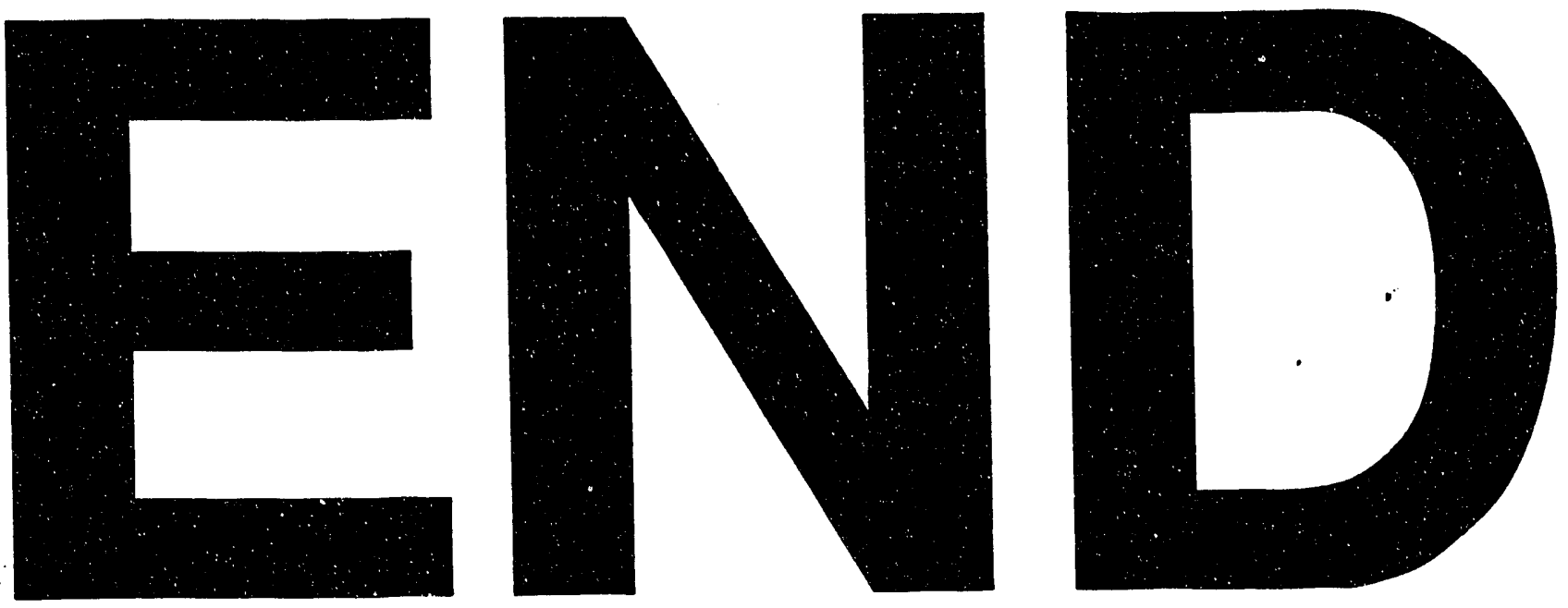
